\title{
MULTIATTRIBUTE EVALUATION OF ORGANIC AND INORGANIC AGRICULTURAL FOOD INVESTMENTS USING FUZZY TOPSIS
}

\author{
Asli SUDER ${ }^{1}$, Cengiz KAHRAMAN²* \\ ${ }^{1}$ Management Engineering, Istanbul Technical University, 34367 Macka Besiktas, Istanbul, Turkey \\ ${ }^{2}$ Industrial Engineering Department, Istanbul Technical University, \\ 34367 Macka Besiktas, Istanbul, Turkey
}

Received 06 March 2015; accepted 08 December 2015

\begin{abstract}
Since people well know the threats of inorganic agriculture to their health, they are more interested in organic agriculture than ever. Organic agriculture is expected to play a major role for a healthy world in the future whereas inorganic agriculture nowadays increases the volume of agricultural production and presents lower priced foods but causes health problems. The agricultural investments are generally evaluated by using linguistic terms since most of the evaluation criteria are intangible and inherently require imprecise data to be used. In this paper, we analyze six types of agricultural investment alternatives using eight different criteria based on linguistic data. One of the most-used multi-criteria decision-making methods, TOPSIS is used under fuzziness for the solution of this problem. A sensitivity analysis is also given to examine the robustness of the decision.
\end{abstract}

Keywords: multiattribute, organic food, inorganic food, investment, fuzzy set, TOPSIS.

JEL Classification: C65, Q18.

\section{Introduction}

Organic agriculture produces fruits and vegetables using environmentally- and animalfriendly farming methods. The food from organic agriculture is high quality, nutritious and contributes to a healthy life. There are various definitions of organic agriculture. For instance, organic agriculture produces food without artificial chemicals but with organic-based chemicals (Legg, Viatte 2001).

Sustainable agriculture uses farming techniques protecting the environment, public health, and animal welfare. Sustainable farming systems should provide a long-term welfare through economical, environmentally friendly and socially acceptable food and other goods and services (Parris 2004).

*Corresponding author. E-mail: kahramanc@itu.edu.tr 
In these days, while a significant increase in inorganic agricultural production is observed, a meaningful increase in demand for organic food appears as well. The growth in demand and consumption of organic foods are mainly because of the increasing number of consumers demanding food quality and safety benefits with organic foods and/or food production systems. Since organic production systems frequently produce lower yields and higher costs, consumers have to pay higher prices for organic food (Leifert 2007).

The benefits of organic farming are now widely accepted in the world. This is the main reason for government support of organic farming. These benefits are (a) lower levels of pollution of surface and ground water (b) reduced energy use and (c) increased density and diversity (Niggli 2007).

Yields generally are lower on organic farms than the conventional farms. Both labor costs and profitability are generally higher due to price premiums and support payments in a lot of countries. Economic comparisons between organic and conventional farms may not be meaningful. The various environmental externalities arising from different farming systems should clearly be taken into account. Thus farmers can make decisions as to the most appropriate system to adopt (OECD 2003).

Decisions for organic or inorganic food farming investments include multi-criteria and multi-experts evaluations. Besides, these criteria may be conflicting and most of them can be evaluated by linguistic terms rather than numerical evaluations. For instance, a possible criterion effects on flora and fauna can be evaluated using linguistic terms such as very poor, poor, good, and very good. These kinds of evaluations can be better handled by the fuzzy set theory based methodologies. For this aim, many fuzzy multi-criteria decision-making methods have been developed in the literature. Fuzzy Analytic Hierarchy Process (AHP), fuzzy TOPSIS, fuzzy VIKOR, fuzzy ELECTRE, fuzzy PROMETHEE, and fuzzy DEMATEL are among these methods.

Little research exists on multi-criteria organic and inorganic food or farming investments. Hayashi (2000) gives a literature review and future perspectives on multiple criteria decision analysis for agricultural resource management. Girardin et al. (2000) propose a multi-criteria decision-making method for the evaluation of arable farming systems. Rozman et al. (2006) present a multi-criteria analysis for the evaluation of spelt food processing alternatives in small organic farms. Parra-Lopez et al. (2007) make a multi-criteria environmental comparison of conventional, organic and integrated olive-growing systems in Spain. Parra-López et al. (2008) use AHP for comparing performances of alternative olive growing systems in Andalusia. Latinopoulos (2009) uses multi-criteria decision analysis for the allocation of land and water resources in irrigated agriculture. Siciliano (2009) studies a multi-criteria evaluation of farming practices under soil degradation in Southern Tuscany, Italy. Masuda et al. (2010) present an application for organic coffee production in Kona, Hawaii by multicriteria decision-making. Castellini et al. (2012) analyze the sustainability of different poultry production systems. The sustainability of the conventional, organic and organic-plus poultry production systems is compared by a multi-criteria decision analysis (MCDA) including the dimensions economic, social, environmental and quality. The examined farming systems show different results with respect to scientists, consumers and producers. Læssøe et al. (2014) discuss how the economic, psychosocial, and relational perspectives converge and 
diverge regarding the purpose of using a multicriteria assessment tool (MCA). Through this multiple-perspective approach, the general idea of MCA is expanded and elaborated to refine the design of an MCA tool for organic food systems. Kastberg (2015) presents a critical discussion of the promises and pitfalls of how multicriteria assessments may be communicated and coconstructed on a coactional, web-based platform for organic foods. As it is clearly seen from the literature review, there is no research on fuzzy multi-criteria decision analysis for organic/inorganic food investments.

This paper aims at selecting the best farming investment decision under multi-criteria and fuzzy environment. The originality of this paper comes from the first time application of a fuzzy multi-criteria decision-making method for organic or inorganic farming investment decisions. Our paper is constructed as follows. Section 1 gives the possible investment criteria and alternatives for agricultural farming investments. Section 2 presents a fuzzy multi-criteria decision-making method, namely fuzzy TOPSIS. Section 3 includes a multi-criteria investment analysis for agricultural farming. Final section gives the conclusions and suggestions for further research.

\section{Investment criteria and alternatives in agricultural farming}

Investment in agriculture is a popular problem of our day. Organic or inorganic farming investments involve many criteria those must be considered before an investment decision is given. Most of these criteria have to be evaluated by linguistic terms rather than numerical values. The considered criteria after a wide literature review have been listed as follows:

Previously applied productions systems and technologies (PAPT): This criterion tries to answer which production technologies have been used in the past for the considered arable field. It is known that an inorganic farming method would make use of pesticide or insecticides to get rid of pests and weeds. This may cause to exterminate the aliveness of the soil. Genetically modified organisms (GMO) change the chemical structure of soil and do not let the original natural structure to be recovered.

Annual average net income (AAI): Inorganic farming generally increases the amount of agricultural production since it uses chemicals and genetically modified organisms (GMO). Besides, the cost of inorganic farming is slightly higher than organic farming as it is illustrated in Figure 1 (Royte 2013). As a result, this causes organic foods be more expensive than inorganic foods.

Increase in labor requirement (ILR): In Turkey, inorganic farming needs more labor requirement when compared with organic farming. The literature provides evidence that labor use changes with respect to the climate conditions and technological requirements. When climate conditions and technological facilities become worse, inorganic farming needs more expenses.

Effects on human health (EHH): Organic food usually contains fewer contaminants, more nutrients less cause food poisoning and it is useful for the environment and human health (Givens et al. 2008).

Effects on flora and fauna (EFF): Suitable habitats for wildlife are only possible with the continuous maintenance of natural areas within and around organic fields and absence of chemical inputs (FAO.org). 
Need for alternation (NA): Alteration is often the physical modification of a site usually to improve or allow agricultural production. Alteration in farming causes the agricultural production level to increase since the chemical components which same plants need decrease in the soil year by year.

Soil characteristics (SC): Soil characteristics have importance from the viewpoint of the type of the agricultural production, e.g. organic and inorganic production. In most applications of inorganic production, minimum level of natural soil is needed; instead, some chemicals are used, which accelerate the growth of plants.

Farmer motivation (FM): The motivational factors which affect a farmer's motivation can be listed as seasonality, community, social interactions, location and distances, economic reasons, environmental concerns, production methods, consumer and producer/vendor connection. Nowadays farmers generally prefer inorganic farming since the economic benefits from this kind of production are relatively larger than organic farming.

In this study, six possible farming investment alternatives have been considered:

Organic field farming (A1): It uses organic manures, and bio-pesticides without inorganic chemicals and pesticides.

Organic farming in greenhouses with soil (A2): This type of farming is applied in greenhouses using organic soil. This type costs more but provides the stable weather conditions.

Integrated Organic Farming Systems (A3): In integrated organic farming, local resources are effectively recycled by involving other components. It includes integrated nutrient and pest management.

Inorganic farming in greenhouses with soil (A4): It is a type of farming using modern technologies aiming optimal nutrition for plants. Greenhouse farming may use crop protection materials to control pests. It is sustainable. Water use is reduced.

Inorganic field farming (A5): This type of farming is an agriculture production method including the use of manmade products such as pesticides, herbicides, etc. It requires less land and water use. It is sustainable.

Inorganic soilless farming in greenhouses (A6): Soilless farming is an artificial production of plants with support and a reservoir for nutrients and water. Inorganic chemicals are dissolved in water and supply all of the nutrients necessary for plants.

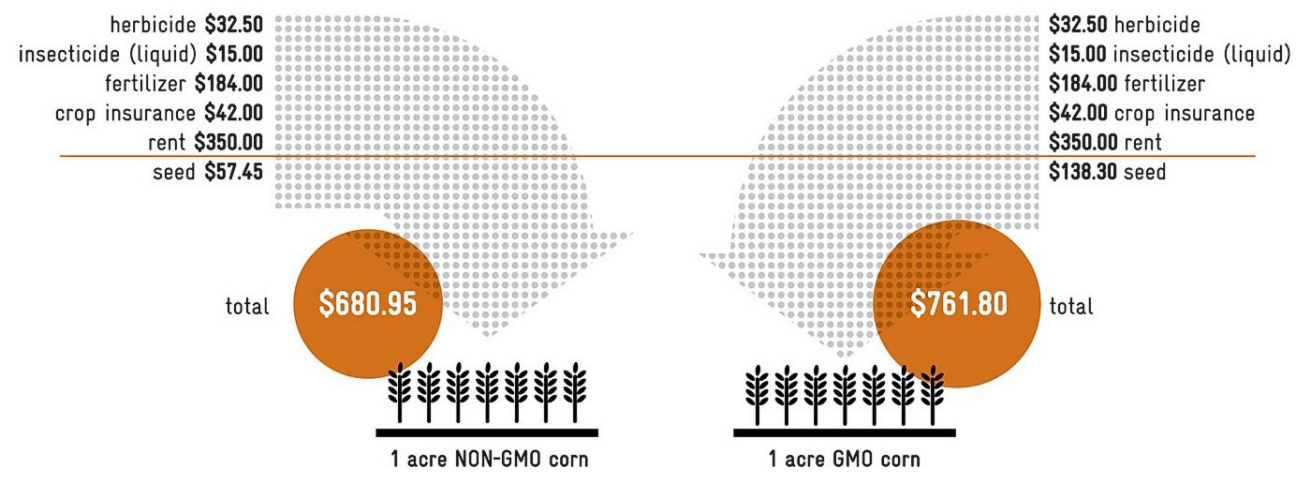

Fig. 1. Costs of 1 acre GMO and Non-GMO corn 


\section{Fuzzy multi-criteria evaluation: fuzzy TOPSIS}

TOPSIS which is one of the most-used classical multi-criteria decision-making methods was developed by Hwang and Yoon (1981). Fuzzy extensions of TOPSIS have been developed by recently used in the analysis of various problems.

Ekmekçioğlu et al. (2010) used a modified fuzzy TOPSIS for the selection of the best municipal solid waste disposal method and site. Chen and Lee (2010) proposed an interval type-2 fuzzy TOPSIS method for the solution of fuzzy multiple criteria decision-making problems. Kutlu and Ekmekçioğlu (2012) used an integrated method including fuzzy TOPSIS and fuzzy AHP to develop a new FMEA which removes the shortcomings of traditional FMEA. Sun (2010) developed an evaluation model based on fuzzy AHP and fuzzy TOPSIS for performance evaluation in a fuzzy environment. Kaya and Kahraman (2011) proposed a fuzzy TOPSIS method for the selection of the best energy technology alternative. Paksoy et al. (2012) used fuzzy AHP and hierarchical fuzzy TOPSIS for prioritizing the organization strategies of distribution channel management in a firm. Kim et al. (2013) developed a fuzzy TOPSIS method for prioritizing the best sites for treated wastewater usage. Roshandel $e t$ al. (2013) evaluated four suppliers using the hierarchical fuzzy TOPSIS approach. Kahraman et al. (2013) evaluated possible higher education investment alternatives using an integrated method of fuzzy AHP and Fuzzy TOPSIS. Taylan et al. (2014) categorized the construction projects by fuzzy AHP and TOPSIS methods. Kannan et al. (2014) proposed a Fuzzy TOPSIS method for the selection among green suppliers for a Brazilian electronics company. Lee et al. (2014) used a fuzzy TOPSIS method based on $\alpha$-cut level sets, aiming at improving the general flood vulnerability approach.

TOPSIS selects the alternative with the shortest distance from the positive ideal solution (PIS) and the farthest from the negative ideal solution (NIS). It can consider various criteria, which might be conflicting and have different units simultaneously.

Consider the decision matrix with $n$ attributes and $m$ alternatives given in Eq. (1). TOPSIS chooses the alternative with the largest value of $C_{i}^{*}$ in Eq. (2) and with the least value of $\mathrm{C}_{i}^{-}$in Eq. (3) by using the vector normalization.

$$
D=\left[\begin{array}{ccccc}
x_{11} & \cdots & x_{1 j} & \cdots & x_{1 n} \\
\vdots & \ddots & \vdots & \ddots & \vdots \\
x_{i 1} & \cdots & x_{i j} & \cdots & x_{i n} \\
\vdots & \ddots & \vdots & \ddots & \vdots \\
x_{m 1} & \cdots & x_{m j} & \cdots & x_{m n}
\end{array}\right] ;
$$




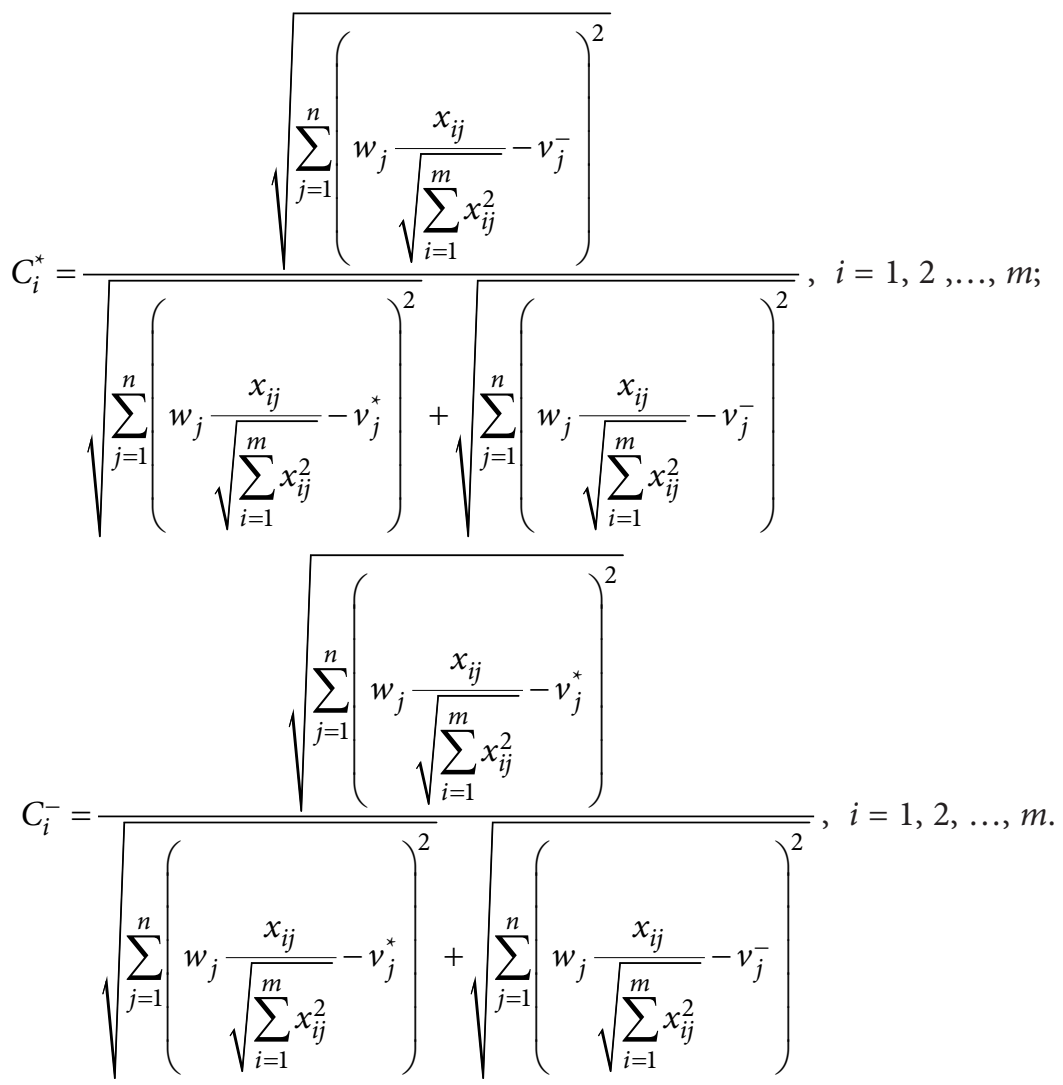

where $i$ represents the number of alternatives $(i=1, \ldots, m)$ and $j$ represents the number of attributes $(j=1, \ldots, n) ; w_{j}$ is the $j$ th attribute's weight; $x_{i j}$ is the value of $j$ th attribute for $i$ th alternative in the decision matrix; $v_{j}^{*}$ is the positive-ideal value of $j$ th attribute; $v_{j}^{-}$is the $j$ th attribute's negative-ideal value.

The steps of fuzzy TOPSIS are given in the following (Yoon, Hwang 1995):

Step 1. Determination of criteria weights and construction of decision matrix: The fuzzy scales given in Tables 1 and 2 are used in the construction of decision matrix.

Table 1. Fuzzy evaluation scale for the weights of criteria

\begin{tabular}{|l|c|}
\hline \multicolumn{1}{|c|}{ Linguistic terms } & Fuzzy scale \\
\hline Absolutely Strong (AS) & $(2,5 / 2,3)$ \\
\hline Very Strong (VS) & $(3 / 2,2,5 / 2)$ \\
\hline Fairly Strong (FS) & $(1,3 / 2,2)$ \\
\hline Slightly Strong (SS) & $(1,1,3 / 2)$ \\
\hline Equal (E) & $(1,1,1)$ \\
\hline Slightly Weak (SW) & $(2 / 3,1,1)$ \\
\hline Fairly Weak (FW) & $(1 / 2,2 / 3,1)$ \\
\hline Very Weak (VW) & $(2 / 5,1 / 2,2 / 3)$ \\
\hline Absolutely Weak (AW) & $(1 / 3,2 / 5,1 / 2)$ \\
\hline
\end{tabular}

Table 2. Fuzzy evaluation scale for the alternatives

\begin{tabular}{|l|c|}
\hline \multicolumn{1}{|c|}{ Linguistic terms } & Fuzzy scale \\
\hline Very Poor (VP) & $(0,0,1)$ \\
\hline Poor (P) & $(0,1,3)$ \\
\hline Medium Poor (MP) & $(1,3,5)$ \\
\hline Fair (F) & $(3,5,7)$ \\
\hline Medium Good (MG) & $(5,7,9)$ \\
\hline Good (G) & $(7,9,10)$ \\
\hline Very Good (VG) & $(9,10,10)$ \\
\hline
\end{tabular}


Step 2. Normalization of the obtained scores.

The linear scale transformation is given in Eq. (4):

$$
r_{i j}=\left\{\begin{array}{cl}
x_{i j} / x_{j}^{*}, \forall j, & \text { for benefit attributes } \\
x_{j}^{-} / x_{i j}, \forall j, & \text { forcost attributes. }
\end{array}\right.
$$

By applying Eq. (4), we can write the normalized decision matrix $(D)$ as:

$$
D=\left[\begin{array}{ccccc}
r_{11} & \cdots & r_{1 j} & \cdots & r_{1 n} \\
\vdots & \ddots & \vdots & \ddots & \vdots \\
r_{i 1} & \cdots & r_{i j} & \cdots & r_{i n} \\
\vdots & \ddots & \vdots & \ddots & \vdots \\
r_{m 1} & \cdots & r_{m j} & \cdots & r_{m n}
\end{array}\right]
$$

In the fuzzy case, the normalized decision matrix is obtained as follows.

Let the minimum value be $\tilde{x}_{j}^{-}=\left(a_{i}^{-}, b_{i}^{-}, c_{i}^{-}, d_{i}^{-}\right)$for cost attributes and the maximum value be $\tilde{x}_{j}^{*}=\left(a_{j}^{*}, b_{j}^{*}, c_{j}^{*}, d_{j}^{*}\right)$ for benefit attributes in the decision matrix, then we have

$$
r_{i j}=\left\{\begin{array}{l}
x_{i j}(\div) x_{j}^{*}=\left(\frac{a_{i j}}{d_{j}^{*}}, \frac{b_{i j}}{c_{j}^{*}}, \frac{c_{i j}}{b_{j}^{*}}, \frac{d_{i j}}{a_{j}^{*}}\right), \text { for benefit attributes } \\
x_{j}^{-}(\div) x_{i j}=\left(\frac{a_{j}^{-}}{d_{i j}}, \frac{b_{i}^{-}}{c_{i j}}, \frac{c_{i}^{-}}{b_{i j}}, \frac{d_{i}^{-}}{F_{i j}}\right), \text { for cost attributes. }
\end{array}\right.
$$

Step 3. Construction of the weighted normalized fuzzy decision matrix.

Eq. (7) is used for the crisp case:

$$
v_{i j}=r_{i j} w_{j}, \forall i, j .
$$

In the fuzzy case, Eq. (8) is used:

$$
\tilde{v}_{i j}=\tilde{r}_{i j}(.) \tilde{w}_{j}=\left\{\begin{array}{l}
\left(\frac{a_{i j}}{d_{j}^{*}} \alpha_{j}, \frac{b_{i j}}{c_{j}{ }^{*}} \beta_{j}, \frac{c_{i j}}{b_{j}^{*}} \gamma_{j}, \frac{d_{i j}}{a_{j}{ }^{*}} \delta_{j}\right), \text { for benefit attributes } \\
\left(\frac{a_{i}^{-}}{d_{i j}} \alpha_{j}, \frac{b_{i}^{-}}{c_{i j}} \beta_{j}, \frac{c_{i}^{-}}{b_{i j}} \gamma_{j}, \frac{d_{i}^{-}}{a_{i j}} \delta_{j}\right), \text { for cost attributes. }
\end{array}\right.
$$

The result of Eq. (8) can be summarized as:

$$
\tilde{V}=\left[\begin{array}{ccccc}
\tilde{v}_{11} & \cdots & \tilde{v}_{1 j} & \cdots & \tilde{v}_{1 n} \\
\vdots & \ddots & \vdots & \ddots & \vdots \\
\tilde{v}_{i 1} & \cdots & \tilde{v}_{i j} & \cdots & \tilde{v}_{i n} \\
\vdots & \ddots & \vdots & \ddots & \vdots \\
\tilde{v}_{m 1} & \cdots & \tilde{v}_{m j} & \cdots & \tilde{v}_{m n}
\end{array}\right]
$$


Step 4. Calculation of the distances from fuzzy PIS and fuzzy NIS for each alternative:

$$
\begin{aligned}
& A^{*}=\left[\tilde{v}_{1}^{*}, \ldots, \tilde{v}_{n}^{*}\right] ; \\
& A^{-}=\left[\tilde{v}_{1}^{-}, \ldots, \tilde{v}_{n}^{-}\right],
\end{aligned}
$$

where $\tilde{v}_{j}^{*}=\max \tilde{v}_{i j}$ and $\tilde{v}_{j}^{-}=\min \tilde{v}_{i j}$.

For fuzzy data, $\tilde{v}_{j}^{*}$ and $\tilde{v}_{j}^{-}$may be obtained through some ranking procedures. Chen (2000) proposed that $\tilde{v}_{j}^{*}=(1,1,1)$ and $\tilde{v}_{j}^{-}=(0,0,0)$, which very much simplifies the calculations. We will prefer Chen's (2000) approach in this paper.

Step 5. Calculation of closeness coefficients $\left(C C_{i}\right)$.

To calculate these coefficients, the separation measures $S_{i}^{*}$ and $S_{i}^{-}$are calculated by Eq. (12) and Eq. (13).

and

$$
S_{i}^{*}=\sum_{j=1}^{n} D_{i j}^{*}, i=1, \ldots, m
$$

$$
S_{i}^{-}=\sum_{j=1}^{n} D_{i j}^{-}, i=1, \ldots, m .
$$

In the crisp case, the difference measures $D_{i j}^{*}$ and $D_{i j}^{-}$are given in Eq. (14) and Eq. (15):

$$
\begin{aligned}
& D_{i j}^{*}=\left|v_{i j}-v_{j}^{*}\right| ; \\
& D_{i j}^{-}=\left|v_{i j}-v_{j}^{-}\right| .
\end{aligned}
$$

For fuzzy data:

$$
D_{i j}^{*}=1-\left\{\sup _{x}\left[\mu_{v_{i j}}(x) \wedge \mu_{v_{j}^{*}}(x)\right]\right\}=1-L_{i j}, \forall j, i,
$$

where the highest degree of similarity of $v_{i j}$ and $v_{j}^{*}$ is $L_{i j}$.

The difference between $\mu_{v_{i j}}(x)$ and $\mu_{v_{i j}^{-}}(x)$ is defined in Eq. (17):

$$
D_{i j}^{-}=1-\left\{\sup _{x}\left[\mu_{v_{i j}}(x) \wedge \mu_{v_{j}^{-}}(x)\right]\right\}=1-L_{i j}, \forall j, i .
$$

Note that $D_{i j}^{*}$ and $D_{i j}^{-}$are crisp numbers.

Thus $S_{i}^{*}$ and $S_{i}^{-}$are obtained as crisp numbers. They are used for the calculation of closseness coefficients as in Eq. (18):

$$
C C_{i}=\frac{S_{i}^{-}}{S_{i}^{*}+S_{i}^{-}} .
$$

The alternative with the largest $C C_{i}$ index is selected.

\section{A multi-criteria investment analysis for agricultural farming}

A farmer in Sakarya, a city in Marmara region of Turkey, who has an arable field of 23,500 $\mathrm{m}^{2}$, wants to decide which food production method he should select. He is confused among many criteria and alternatives. A team of five experts from Republic of Turkey Ministry of Food, Agriculture and Livestock helps farmers giving this kind of decisions by multi-criteria approaches. The team decided to use the criteria and alternatives given in Section 1. Table 3 shows the evaluations of these experts for the criteria, based on the scale in Table 1. 
Table 3. Linguistic evaluation scores for the weights of criteria

\begin{tabular}{|c|c|c|c|c|c|c|c|c|}
\hline \multirow{2}{*}{ Expert No } & \multicolumn{9}{|c|}{ Criteria } \\
\cline { 2 - 9 } & FM & PAPT & AAI & ILR & NA & EHH & EFF & SC \\
\hline 1 & FS & FS & VS & E & SS & VS & VS & SW \\
\hline 2 & VS & VS & FS & E & FS & AS & VS & AW \\
\hline 3 & FS & SS & VS & SS & SS & VS & FS & FW \\
\hline 4 & VS & FS & VS & FS & FS & FS & VS & E \\
\hline 5 & SS & FS & FS & E & SS & AS & VS & VW \\
\hline
\end{tabular}

Table 4. Evaluation of alternatives with respect to the criteria

\begin{tabular}{|l|c|c|c|c|c|c|c|c|}
\hline \multirow{2}{*}{\multicolumn{1}{c|}{ Alternatives }} & \multicolumn{7}{c|}{ Criteria } \\
\cline { 2 - 10 } & FM & PAPT & AAI & ILR & NA & EHH & EFF & SC \\
\hline A1. Organic field farming & G & VG & MG & VG & MP & VG & VG & MG \\
\hline $\begin{array}{l}\text { A2. Organic farming in greenhouses } \\
\text { with soil }\end{array}$ & MG & G & F & MG & MP & VG & VG & MG \\
\hline A3. Integrated Organic Farming System & G & G & F & G & P & MG & VG & G \\
\hline $\begin{array}{l}\text { A4. Inorganic farming in greenhouses } \\
\text { with soil }\end{array}$ & F & FS & G & MG & G & P & MG & MG \\
\hline A5. Inorganic field farming & MG & MG & VG & G & MG & P & P & MG \\
\hline $\begin{array}{l}\text { A6. Inorganic soilless farming } \\
\text { in greenhouses }\end{array}$ & MP & VP & MG & MP & G & VP & F & G \\
\hline
\end{tabular}

Table 4 gives the decision matrix including the experts compromised lingusitic evaluations for the alternatives with respect to the criteria.

Table 5 presents the corresponding numerical values of the linguistic evaluations in Table 4 . Table 6 shows the normalized decision matrix. All the criteria are assumed to be benefit criteria and scored with respect to this assumption. For the criterion FM, since the largest possible value is 7 , all the values of FM are divided by 7 .

The criteria weights are determined by averaging the linguistic evaluations made by the five experts in Table 3. For instance, the weight of the criterion FM is calculated as follows $(\mathrm{FS}+\mathrm{VS}+\mathrm{FS}+\mathrm{VS}+\mathrm{SS}) / 5=[(1,3 / 2,2)+(3 / 2,2,5 / 2)+(1,3 / 2,2)+((3 / 2,2,5 / 2)+(1,1$, $3 / 2)] / 5=(6,8,10.5) / 5=(1.2,1.6,2.1)$. These values for the other criteria PAPT, AAI, ILR, NA, EHH, EFF, and SC are (1.1, 1.5, 2.0), (1.0, 1.2, 1.7), (1.3, 1.8, 2.3), (1.0, 1.1, 1.3), (1.6, 2.1, $2.6),(1.4,1.9,2.4)$, and $(0.58,0.71,0.83)$, respectively. Later, defuzzification of these fuzzy numbers by averaging the triple values of each number and then normalizing the defuzzified values gives us the weights $0.135,0.127,0.107,0.149,0.094,0.173,0.157$, and 0.059 for FM, PAPT, AAI, ILR, NA, EHH, EFF, and SC, respectively.

Table 7 gives the weighted normalized decision matrix. Tables 8 and 9 present the distances to the positive and negative ideal solutions for each alternative, respectively.

Table 10 gives the similarity coefficient to ideal solution of each alternative. 
Table 5. Fuzzy decision matrix and criteria weights

\begin{tabular}{|c|c|c|c|c|c|c|c|c|c|c|c|c|c|c|c|c|c|c|c|c|c|c|c|}
\hline \multirow{3}{*}{$\begin{array}{l}\text { Alternatives } \\
\text { A1. Organic } \\
\text { field farming }\end{array}$} & \multicolumn{23}{|c|}{ Criteria } \\
\hline & \multicolumn{3}{|c|}{$\mathrm{FM}$} & \multicolumn{3}{|c|}{ PAPT } & \multicolumn{3}{|c|}{ AAI } & \multicolumn{3}{|c|}{ ILR } & \multicolumn{3}{|c|}{ NA } & \multicolumn{3}{|c|}{$\mathrm{EHH}$} & \multicolumn{2}{|c|}{ EFF } & \multicolumn{3}{|c|}{ SC } \\
\hline & 5 & 6 & 7 & 6 & 7 & 7 & 5 & 6 & 7 & 4 & 5 & 6 & 5 & 6 ? & 7 & 5 & 6 & 7 & \begin{tabular}{l|l}
4 & 5
\end{tabular} & 6 & 5 & 6 & 7 \\
\hline $\begin{array}{l}\text { A2. Organic } \\
\text { farming in } \\
\text { greenhouses } \\
\text { with soil }\end{array}$ & 1 & 2 & 3 & 4 & 5 & 6 & 4 & 5 & 6 & 4 & 5 & 6 & 1 & 2 & 3 & 4 & 5 & 6 & 5 & 7 & 4 & 5 & 6 \\
\hline $\begin{array}{l}\text { A3. Integrated } \\
\text { Organic } \\
\text { Farming } \\
\text { System }\end{array}$ & 4 & 5 & 6 & 5 & 6 & 7 & 4 & 5 & 6 & 5 & 6 & 7 & 4 & 5 & 6 & 4 & 5 & 6 & \begin{tabular}{l|l}
5 & 6
\end{tabular} & 7 & 4 & 5 & 6 \\
\hline $\begin{array}{l}\text { A4. Inorganic } \\
\text { farming in } \\
\text { greenhouses } \\
\text { with soil }\end{array}$ & 1 & 2 & 3 & 4 & 5 & 6 & 3 & 4 & 5 & 2 & 3 & 4 & 2 & 3 & 4 & 3 & 4 & 5 & 4 & 6 & 2 & 3 & 4 \\
\hline $\begin{array}{l}\text { A5. Inorganic } \\
\text { field farming }\end{array}$ & 4 & 5 & 6 & 4 & 5 & 6 & 4 & 5 & 6 & 2 & 3 & 4 & 2 & 3 & 4 & 3 & 4 & 5 & \begin{tabular}{l|l}
3 & 4
\end{tabular} & 5 & 3 & 4 & 5 \\
\hline $\begin{array}{l}\text { A6. Inorganic } \\
\text { soilless } \\
\text { farming in } \\
\text { greenhouses }\end{array}$ & 5 & 6 & 7 & 4 & 5 & 6 & 2 & 3 & 4 & 2 & 3 & 4 & 5 & 6 & 7 & 3 & 4 & 5 & 2 & 4 & 3 & 4 & 5 \\
\hline $\begin{array}{l}\text { Criteria } \\
\text { weights (w) }\end{array}$ & & 0.135 & & & 127 & & & .107. & & & .149 & & & .094 & & & 173 & & 0.15 & 57 & & 0.059 & \\
\hline
\end{tabular}

Table 6. Normalized decision matrix

\begin{tabular}{|c|c|c|c|c|c|c|c|c|c|c|c|c|c|c|c|c|c|c|c|c|c|c|c|c|}
\hline$\stackrel{\mathscr{J}}{\Xi}$ & \multicolumn{24}{|c|}{ Criteria } \\
\hline$\frac{\vec{\Phi}}{4}$ & & FM & & & PAPT & & & AAI & & & ILR & & & NA & & & EHH & & & EFF & & & SC & \\
\hline A1 & 0.71 & 0.86 & 1.00 & \begin{tabular}{|l|}
0.86 \\
\end{tabular} & \begin{tabular}{|l|l|}
1.00 \\
\end{tabular} & 1.00 & 0.71 & \begin{tabular}{|l|}
0.86 \\
\end{tabular} & 1.00 & 0.57 & 0.71 & 0.86 & \begin{tabular}{|l|}
0.71 \\
\end{tabular} & \begin{tabular}{|l|}
0.86 \\
\end{tabular} & 1.00 & $\mid$\begin{tabular}{|l|}
0.71 \\
\end{tabular} & \begin{tabular}{|l|}
0.86 \\
\end{tabular} & 1.00 & \begin{tabular}{|l|}
0.57 \\
\end{tabular} & \begin{tabular}{|l|}
0.71 \\
\end{tabular} & 0.86 & 0.71 & 0.86 & 1.00 \\
\hline A2 & 0.14 & 0.29 & \begin{tabular}{|l|}
0.43 \\
\end{tabular} & \begin{tabular}{|l|}
0.57 \\
\end{tabular} & \begin{tabular}{|l|}
0.71 \\
\end{tabular} & 0.86 & \begin{tabular}{|l|}
0.57 \\
\end{tabular} & \begin{tabular}{|l|}
0.71 \\
\end{tabular} & 0.86 & 0.57 & | & 0.86 & \begin{tabular}{|l|}
0.14 \\
\end{tabular} & \begin{tabular}{|l|}
0.29 \\
\end{tabular} & \begin{tabular}{|l|}
0.43 \\
\end{tabular} & \begin{tabular}{|l|}
0.57 \\
\end{tabular} & 0.71 & \begin{tabular}{|l|}
0.86 \\
\end{tabular} & \begin{tabular}{|l|}
0.71 \\
\end{tabular} & 0.86 & \begin{tabular}{|l|}
1.00 \\
\end{tabular} & 0.57 & \begin{tabular}{|l|}
0.71 \\
\end{tabular} & 0.86 \\
\hline A3 & $\mid 0.57$ & 0.71 & 0.86 & $\mid 0.71$ & 0.86 & 1.00 & $\mid 0.57$ & 0.71 & 0.86 & $0.71 \mid c$ & \begin{tabular}{|l|}
0.86 \\
\end{tabular} & 1.00 & \begin{tabular}{|l|l|}
0.57 \\
\end{tabular} & 0.71 & \begin{tabular}{|l|l|}
0.86 \\
\end{tabular} & $\mid 0.57$ & 0.71 & \begin{tabular}{|l|}
0.86 \\
\end{tabular} & \begin{tabular}{|l|}
0.71 \\
\end{tabular} & 0.86 & 1.00 & $\mid 0.57$ & $\mid 0.71$ & 0.86 \\
\hline A4 & 0.14 & 0.29 & 0.43 & \begin{tabular}{|l|}
0.57 \\
\end{tabular} & \begin{tabular}{|l|}
0.71 \\
\end{tabular} & $\mid 0.86$ & \begin{tabular}{|l|}
0.43 \\
\end{tabular} & \begin{tabular}{|l|}
0.57 \\
\end{tabular} & 0.71 & \begin{tabular}{|c|}
0.29 \\
\end{tabular} & 0.43 & \begin{tabular}{|l|}
0.57 \\
\end{tabular} & 0.29 & \begin{tabular}{|l|}
0.43 \\
\end{tabular} & 0.57 & 0.43 & 0.57 & \begin{tabular}{|l|l}
0.71 \\
\end{tabular} & 0.57 & 0.71 & \begin{tabular}{|l|}
0.86 \\
\end{tabular} & 0.29 & \begin{tabular}{|l|}
0.43 \\
\end{tabular} & 0.57 \\
\hline A5 & 0.57 & 0.71 & 0.86 & 0.57 & 0.71 & 0.86 & 0.57 & 0.71 & 0.86 & 0.29 & 0.43 & \begin{tabular}{|l|} 
\\
\end{tabular} & 0.29 & \begin{tabular}{|l|}
0.43 \\
\end{tabular} & 0.57 & 0.43 & 0.57 & \begin{tabular}{|l|l}
0.71 \\
\end{tabular} & 0.43 & 0.57 & 0.71 & $\mid 0.43$ & $\mid 0.57$ & \begin{tabular}{|l|} 
\\
\end{tabular} \\
\hline A6 & 0.71 & \begin{tabular}{|l|}
0.86 \\
\end{tabular} & 1.00 & 0.57 & 0.71 & 0.86 & \begin{tabular}{|l|}
0.29 \\
\end{tabular} & 0.43 & 0.57 & \begin{tabular}{|l|l|}
0.29 & \\
\end{tabular} & \begin{tabular}{|l|}
0.43 \\
\end{tabular} & \begin{tabular}{|l|l|}
0.57 \\
\end{tabular} & \begin{tabular}{|l|}
0.71 \\
\end{tabular} & \begin{tabular}{|l|}
0.86 \\
\end{tabular} & 1.00 & \begin{tabular}{|l|}
0.43 \\
\end{tabular} & 0.57 & \begin{tabular}{|l|}
0.71 \\
\end{tabular} & \begin{tabular}{|l|}
0.29 \\
\end{tabular} & 0.43 & 0.57 & \begin{tabular}{|l|}
0.43 \\
\end{tabular} & 0.57 & 0.71 \\
\hline
\end{tabular}

Table 7. Fuzzy weighted normalized decision matrix

\begin{tabular}{|c|c|c|c|c|c|c|c|c|c|c|c|c|c|c|c|c|c|c|c|c|c|c|c|c|}
\hline \multirow{2}{*}{ 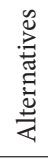 } & \multicolumn{24}{|c|}{ Criteria } \\
\hline & & FM & & & PAPT & & & AAI & & & ILR & & & NA & & & EHH & & & EFF & & & SC & \\
\hline A1 & 0.10 & 0.12 & 0.14 & 0.11 & 0.13 & 0.13 & 0.08 & 0.09 & 0.11 & 0.09 & 0.11 & \begin{tabular}{|l|l|}
0.13 \\
\end{tabular} & 0.07 & \begin{tabular}{|l|}
0.08 \\
\end{tabular} & 0.09 & 0.12 & 0.15 & 0.17 & 0.09 & 0.11 & 0.13 & 0.04 & 0.05 & 0.06 \\
\hline A2 & 0.02 & 0.04 & 0.06 & \begin{tabular}{|l|l|} 
\\
\end{tabular} & 0.09 & 0.11 & \begin{tabular}{|l|}
0.06 \\
\end{tabular} & 0.08 & 0.09 & 0.09 & 0.11 & \begin{tabular}{|l|l|}
0.13 \\
\end{tabular} & 0.01 & 0.03 & \begin{tabular}{|l|}
0.04 \\
\end{tabular} & 0.10 & 0.12 & 0.15 & 0.11 & \begin{tabular}{|l|}
0.13 \\
\end{tabular} & 0.16 & 0.03 & \begin{tabular}{|l|}
0.04 \\
\end{tabular} & 0.05 \\
\hline A3 & 0.08 & 0.10 & 0.12 & 0.09 & 0.11 & 0.13 & 0.06 & 0.08 & 0.09 & 0.11 & 0.13 & \begin{tabular}{|l|l|} 
& \\
\end{tabular} & 0.05 & 0.07 & \begin{tabular}{|l|}
0.08 \\
\end{tabular} & 0.10 & 0.12 & 0.15 & 0.11 & \begin{tabular}{|l|}
0.13 \\
\end{tabular} & 0.16 & 0.03 & \begin{tabular}{|l|}
0.04 \\
\end{tabular} & 0.05 \\
\hline A4 & 0.02 & 0.04 & 0.06 & \begin{tabular}{|l|l|}
0.07 \\
\end{tabular} & 0.09 & 0.11 & 0.05 & 0.06 & 0.08 & 0.04 & 0.06 & 0.09 & 0.03 & 0.04 & \begin{tabular}{|l|}
0.05 \\
\end{tabular} & 0.07 & 0.10 & 0.12 & \begin{tabular}{|l|}
0.09 \\
\end{tabular} & 0.11 & 0.13 & 0.02 & 0.03 & 0.03 \\
\hline A5 & 0.08 & 0.10 & 0.12 & \begin{tabular}{|l|l|}
0.07 \\
\end{tabular} & 0.09 & 0.11 & \begin{tabular}{|l|}
0.06 \\
\end{tabular} & 0.08 & 0.09 & 0.04 & 0.06 & 0.09 & 0.03 & 0.04 & \begin{tabular}{|l|}
0.05 \\
\end{tabular} & 0.07 & 0.10 & \begin{tabular}{|l|}
0.12 \\
\end{tabular} & 0.07 & \begin{tabular}{|l|} 
\\
\end{tabular} & 0.11 & \begin{tabular}{|l|}
0.03 \\
\end{tabular} & 0.03 & 0.04 \\
\hline A6 & 0.10 & 0.12 & 0.14 & \begin{tabular}{|l|}
0.07 \\
\end{tabular} & 0.09 & $\mid 0.11$ & \begin{tabular}{|l|} 
\\
\end{tabular} & 0.05 & 0.06 & 0.04 & 0.06 & \begin{tabular}{|l|}
0.09 \\
\end{tabular} & 0.07 & 0.08 & \begin{tabular}{|l|l|}
0.09 \\
\end{tabular} & 0.07 & 0.10 & 0.12 & 0.04 & 0.07 & 0.09 & 0.03 & 0.03 & 0.04 \\
\hline
\end{tabular}


Table 8. Distances to positive ideal solutions

\begin{tabular}{|c|c|c|c|c|c|c|c|c|c|}
\hline \multirow{2}{*}{ Alternatives } & \multicolumn{10}{|c|}{ Criteria } \\
\cline { 2 - 11 } & FM & PAPT & AAI & ILR & NA & EHH & EFF & SC & Total \\
\hline A1 & 0.884 & 0.879 & 0.908 & 0.894 & 0.919 & 0.852 & 0.888 & 0.949 & 7.175 \\
\hline A2 & 0.962 & 0.909 & 0.924 & 0.894 & 0.973 & 0.877 & 0.866 & 0.958 & 7.362 \\
\hline A3 & 0.904 & 0.891 & 0.924 & 0.872 & 0.933 & 0.877 & 0.866 & 0.958 & 7.224 \\
\hline A4 & 0.962 & 0.909 & 0.939 & 0.936 & 0.960 & 0.901 & 0.888 & 0.975 & 7.470 \\
\hline A5 & 0.904 & 0.909 & 0.924 & 0.936 & 0.960 & 0.901 & 0.910 & 0.966 & 7.411 \\
\hline A6 & 0.884 & 0.909 & 0.954 & 0.936 & 0.919 & 0.901 & 0.933 & 0.966 & 7.404 \\
\hline
\end{tabular}

Table 9. Distances to negative ideal solution

\begin{tabular}{|c|c|c|c|c|c|c|c|c|c|}
\hline \multirow{2}{*}{ Alternatives } & \multicolumn{10}{|c|}{ Criteria } \\
\cline { 2 - 11 } & FM & PAPT & AAI & ILR & NA & EHH & EFF & SC & Total \\
\hline A1 & 0.117 & 0.121 & 0.093 & 0.108 & 0.081 & 0.150 & 0.114 & 0.051 & 0.834 \\
\hline A2 & 0.042 & 0.092 & 0.077 & 0.108 & 0.029 & 0.125 & 0.136 & 0.043 & 0.652 \\
\hline A3 & 0.098 & 0.110 & 0.077 & 0.129 & 0.068 & 0.125 & 0.136 & 0.043 & 0.786 \\
\hline A4 & 0.042 & 0.092 & 0.062 & 0.066 & 0.042 & 0.101 & 0.114 & 0.026 & 0.545 \\
\hline A5 & 0.098 & 0.092 & 0.077 & 0.066 & 0.042 & 0.101 & 0.092 & 0.034 & 0.602 \\
\hline A6 & 0.117 & 0.092 & 0.048 & 0.066 & 0.081 & 0.101 & 0.070 & 0.034 & 0.609 \\
\hline
\end{tabular}

Table 10. Similarity coefficients to ideal solution

\begin{tabular}{|c|c|c|}
\hline Alternatives & Similarity coefficients to ideal solution & Rank \\
\hline A1 & 0.104 & 1 \\
\hline A2 & 0.081 & 3 \\
\hline A3 & 0.098 & 2 \\
\hline A4 & 0.068 & 6 \\
\hline A5 & 0.075 & 5 \\
\hline A6 & 0.076 & 4 \\
\hline
\end{tabular}

According to the results in Table 10, the order from the best to the worst is A1 > A3 > A2 $>$ A6 $>$ A5 $>$ A4. Organic field farming is suggested to the farmer as the best alternative. Integrated organic farming system has the second order while organic farming in greenhouses with soil does the third order. Inorganic farming alternatives A6, A5, and A4 have the later orders.

A sensitivity analysis is needed to see the robustness of the decision. Table 11 shows the results of the sensitivity analysis for three additional cases. Criteria weights- 0 represents the present weights assigned by the experts. Organic field farming always takes the first order even significant changes in criteria weights occur. Even significant changes were made in the weights of the criteria, the order has not changed and it is still A1 > A3 > A2 > A6 > A5 > A4. This means that our decision is a robust decision. 
Table 11. Sensitivity analysis

\begin{tabular}{|c|c|c|c|c|c|c|c|c|c|c|c|c|c|c|}
\hline \multirow{3}{*}{$\begin{array}{c}\text { Cases } \\
\text { Criteria Weights-0 }\end{array}$} & \multicolumn{8}{|c|}{ Criteria } & \multirow{2}{*}{\multicolumn{6}{|c|}{$\begin{array}{l}\text { Alternative rankings } \\
\text { (from the best to the worst) }\end{array}$}} \\
\hline & FM & PAPT & AAI & ILR & NA & $\mathrm{EHH}$ & EFF & SC & & & & & & \\
\hline & 0.135 & 0.127 & 0.107 & 0.149 & 0.094 & 0.173 & 0.157 & 0.059 & 1 & 3 & & & & 4 \\
\hline Criteria Weights- 1 & 0.125 & 0.125 & 0.125 & 0.125 & 0.125 & 0.125 & 0.125 & 0.125 & 1 & & & & & 4 \\
\hline Criteria Weights-2 & 0.145 & 0.127 & 0.107 & 0.139 & 0.094 & 0.163 & 0.167 & 0.059 & 1 & 3 & & & & 4 \\
\hline Criteria Weights-3 & 0.125 & 0.127 & 0.107 & 0.159 & 0.094 & 0.183 & 0.147 & 0.059 & 1 & 3 & 2 & & the & 4 \\
\hline
\end{tabular}

A Comparative analysis using crisp TOPSIS is given below. In crisp analyses, the experts use their most expected values instead of fuzzy numbers. For instance, if it is FS in the fuzzy case, the corresponding value would be the most possible value, 1.5. Based on this assumption, the above analysis is repeated and the obtained results are given in Table 12.

Table 12. Similarity coefficients to ideal solution in the crisp case

\begin{tabular}{|c|c|c|}
\hline Alternatives & Similarity coefficients to ideal solution & Rank \\
\hline A1 & 0.118 & 1 \\
\hline A2 & 0.090 & 3 \\
\hline A3 & 0.112 & 2 \\
\hline A4 & 0.074 & 6 \\
\hline A5 & 0.08080 & 5 \\
\hline A6 & 0.08497 & 4 \\
\hline
\end{tabular}

In the crisp case, even the similarity coefficients changed, the order of the alternatives has not changed and it is still A1 > A3 > A2 > A6 > A5 > A4. This may not be the case for every problem, especially in case the nonsymmetrical fuzzy numbers are used in the fuzzy analysis.

\section{Conclusions}

In these days, the products of organic farming are demanded much more than ever. Our multi-criteria decision-making model shows that organic field farming, organic farming in greenhouses with soil, and integrated organic farming system take the first three orders when they are compared with the alternatives of inorganic farming. If a single criterion analysis based on the criterion annual average net income (AAI) had been made, it is certain that the alternatives of inorganic farming would take the first three orders. Investors generally use the monetary criteria ignoring the nonmonetary issues and this causes short-term and nonstrategic decisions be given for agricultural investments.

Experts usually prefer making linguistic evaluations rather than making exact numerical assignments. For this reason we have selected a fuzzy multi-criteria decision-making method and the experts really enjoyed this method because of its appropriateness for their evaluations. We have not forced them for exact numerical evaluations whittling the ones in their minds. 
For further study, we suggest more criteria to be added to our proposed model. There are also other possible multi-criteria methods which can be extended to use under fuzziness. These may be fuzzy analytic hierarchy process, fuzzy VIKOR, fuzzy ELECTRE, etc. The extensions of ordinary fuzzy sets such as hesitant fuzzy sets, intuitionistic fuzzy sets, and type-2 fuzzy sets can be used to expand this study.

\section{References}

Castellini, C.; Boggia, A.; Cortina, C.; Bosco, A. D.; Paolotti, L.; Novelli, E.; Mugnai, C. 2012. A multicriteria approach for measuring the sustainability of different poultry production systems, Journal of Cleaner Production 37: 192-201. https://doi.org/10.1016/j.jclepro.2012.07.006

Chen, C.-T. 2000. Extensions of the TOPSIS for group decision-making under fuzzy environment, Fuzzy Sets and Systems 114: 1-9. https://doi.org/10.1016/S0165-0114(97)00377-1

Chen, S.-M.; Lee, L.-W. 2010. Fuzzy multiple attributes group decision-making based on the interval type-2 TOPSIS method, Expert Systems with Applications 37: 2790-2798. https://doi.org/10.1016/j.eswa.2009.09.012

Ekmekçioğlu, M.; Kaya, T.; Kahraman, C. 2010. Fuzzy multicriteria disposal method and site selection for municipal solid waste, Waste Management 30: 1729-1736. https://doi.org/10.1016/j.wasman.2010.02.031

FAO. org. 2015. Organic agriculture [online], [cited 14 September 2015]. Available from Internet: http:// www.fao.org/organicag/oa-faq/oa-faq6/en/

Girardin, P.; Bockstaller, C.; der Werf, H. V. 2000. Assessment of potential impacts of agricultural practices on the environment: the AGRO ${ }^{\star} \mathrm{ECO}$ method, Environmental Impact Assessment Review 20(2): 227-239. https://doi.org/10.1016/S0195-9255(99)00036-0

Givens, D. I.; Baxter, S.; Minihane, A. M.; Shaw, E. (Eds.). 2008. Health benefits of organic food: effects of the environment. CAB International.

Hayashi, K. 2000. Multi-criteria analysis for agricultural resource management: a critical survey and future perspectives, European Journal of Operational Research 122: 486-500. https://doi.org/10.1016/S0377-2217(99)00249-0

Hwang, C. L.; Yoon, K. 1981. Multiple attribute decision making: methods and applications. SpringerVerlag, New York. https://doi.org/10.1007/978-3-642-48318-9

Kahraman, C.; Suder, A.; Cebi, S. 2013. Fuzzy multi-criteria and multi-experts evaluation of government investments in higher education: the case of Turkey, Technological and Economic Development of Economy 19(4): 549-569. https://doi.org/10.3846/20294913.2013.837110

Kannan, D.; Jabbour, A. B. L. S.; Jabbour, C. J. C. 2014. Selecting green suppliers based on GSCM practices: using fuzzy TOPSIS applied to a Brazilian electronics company, European Journal of Operational Research 233(2): 432-447. https://doi.org/10.1016/j.ejor.2013.07.023

Kastberg, P. 2015. Promoting communication, participation, and learning with regard to organic food products: a communication theoretical approach, Ecology and Society 20(1), article number 3. https://doi.org/10.5751/ES-07139-200103

Kaya, T.; Kahraman, C. 2011. Multicriteria decision making in energy planning using a modified fuzzy TOPSIS methodology, Expert Systems with Applications 38(6): 6577-6585. https://doi.org/10.1016/j.eswa.2010.11.081

Kim, Y.; Chung, E.-S.; Jun, S.-M.; Kim, S. U. 2013. Prioritizing the best sites for treated wastewater instream use in an urban watershed using fuzzy TOPSIS, Resources, Conservation and Recycling 73: 23-32. https://doi.org/10.1016/j.resconrec.2012.12.009 
Kutlu, A. C.; Ekmekçioğlu, M. 2012. Fuzzy failure modes and effects analysis by using fuzzy TOPSISbased fuzzy AHP, Expert Systems with Applications 39(1): 61-67.

https://doi.org/10.1016/j.eswa.2011.06.044

Læssøe, J.; Ljungdalh, A. K.; Alrøe, H. F.; Noe, E.; Christensen, T.; Dubgaard, A.; Olsen, S. B.; Kærgård, N.; Kastberg, P. 2014. Three perspectives on motivation and multicriteria assessment of organic food systems, Ecology and Society 19(3), article number 7. https://doi.org/10.5751/ES-06397-190307

Latinopoulos, D. 2009. Multicriteria decision-making for efficient water and land resources allocation in irrigated agriculture, Environment, Development and Sustainability 11: 329-343. https://doi.org/10.1007/s10668-007-9115-2

Lee, G.; Jun, K. S.; Chung, E.-S. 2014. Robust spatial flood vulnerability assessment for Han River using fuzzy TOPSIS with $\alpha$-cut level set, Expert Systems with Applications 41(2): 644-654. https://doi.org/10.1016/j.eswa.2013.07.089

Legg, W.; Viatte, G. 2001. Farming systems for sustainable agriculture. OECD Observer, Paris, France.

Leifert, C. 2007. Introduction, in J. Cooper, U. Niggli, C. Leifert (Eds.). Handbook of organic foodsafety and quality. CRC Press, 1-6.

Masuda, T. A. D. A.; Yanagida, J. F.; Moncur, J. E. T.; El-Swaify, S. A. 2010. An application of multicriteria decision making incorporating stochastic production frontiers: a case study of organic coffee production in Kona, Hawaii, Natural resource modeling 23(1): 22-47. https://doi.org/10.1111/j.1939-7445.2009.00055.x

Niggli, U. 2007. History and concepts of food quality and safety in organic food production and processing, in J. Cooper, U. Niggli, C. Leifert (Eds.). Handbook of organic foodsafety and quality. CRC Press, 9-24.

OECD. 2003. Conclusions and recommendations, organic agriculture: sustainability, markets and policies. CABI Publishing, 1-9.

Paksoy, T.; Pehlivan, N. Y.; Kahraman, C. 2012. Organizational strategy development in distribution channel management using fuzzy AHP and hierarchical fuzzy TOPSIS, Expert Systems with Applications 39(3): 2822-2841. https://doi.org/10.1016/j.eswa.2011.08.142

Parra-Lopez, C.; Calatrava-Requena, J.; de-Haro-Gimenez, T. 2007. A multi-criteria evaluation of the environmental performances of conventional, organic and integrated olive-growing systems in the south of Spain based on experts' knowledge, Renewable Agriculture and Food Systems 22(3): 189-203. https://doi.org/10.1017/S1742170507001731

Parra-López, C.; Calatrava-Requena, J.; de-Haro-Giménez, T. 2008. A systemic comparative assessment of the multifunctional performance of alternative olive systems in Spain within an AHP-extended framework, Ecological Economics 64: 820-834. https://doi.org/10.1016/j.ecolecon.2007.05.004

Parris, K. 2004. Lessons from the OECD workshop on biomass and agriculture, greenhouse gas emissions and abrupt climate change: positive options and robust policy, in OECD-OCDE Conference, 30 September-1 October 2004, Paris, France.

Roshandel, J.; Miri-Nargesi, S. S.; Hatami-Shirkouhi, L. 2013. Evaluating and selecting the supplier in detergent production industry using hierarchical fuzzy TOPSIS, Applied Mathematical Modelling 37(24): 10170-10181. https://doi.org/10.1016/j.apm.2013.05.043

Royte, E. 2013. The post-GMO Economy [online], [cited 10 September 2014]. Available from Internet: http://modernfarmer.com/2013/12/post-gmo-economy/

Rozman, C.; Pazek, K.; Bavec, F.; Bavec, M.; Turk, J.; Majkovic, D. 2006. A multi-criteria analysis of spelt food processing alternatives on small organic farms, Journal of Sustainable Agriculture 28(2): 159-179. https://doi.org/10.1300/J064v28n02_12 
Siciliano, G. 2009. Social multicriteria evaluation of farming practices in the presence of soil degradation. A case study in Southern Tuscany, Italy, Environment, Development and Sustainability 11(6): 1107-1133. https://doi.org/10.1007/s10668-008-9169-9

Sun, C.-C. 2010. A performance evaluation model by integrating fuzzy AHP and fuzzy TOPSIS methods, Expert Systems with Applications 37: 7745-7754. https://doi.org/10.1016/j.eswa.2010.04.066

Taylan, O.; Bafail, A. O.; Abdulaal, R. M. S.; Kabli, M. R. 2014. Construction projects selection and risk assessment by fuzzy AHP and fuzzy TOPSIS methodologies, Applied Soft Computing 17: 105-116. https://doi.org/10.1016/j.asoc.2014.01.003

Yoon, K. P.; Hwang, C.-L. 1995. Multiple attribute decision making: an introduction. SAGE Publications, no: 104. 